\title{
Bio-based Hydrogel Formed by Gamma Irradiation
}

\author{
A.A. El-Gendy, H. Abou-Yousef, A.M. Adel* and N. \\ El-Shinnawy \\ Cellulose and Paper Department, National Research \\ Centre, 33 El-Bohouth Street,Dokki, Giza 12622, Egypt.
}

\begin{abstract}
ARBOXYMETHYL chitosan $(\mathrm{CMCt})$ was synthesized through carboxymethylation reaction for chitosan. The prepared (CMCt) was subjected to crosslinking reaction by using $\gamma$ - radiation. Different process parameters were investigated to clarify the effect of radiation dose, $\mathrm{pH}$, and time upon the gel fraction and swelling properties of the produced hydrogels. The gel fraction was reduced after radiation dose $20 \mathrm{KG}$. The swelling\% was dependent on the paste concentrations. At higher paste concentrations, 30- 40\% higher doses of $\gamma$ - radiation, 20 $\mathrm{KG}$, were required for optimum swelling. The high concentration paste, $40 \%$, showed superior swelling in alkaline medium, $\mathrm{pH}>8$, while lower concentration paste manifested optimum swelling in neutral medium, $\mathrm{pH}=7$. The prepared $(\mathrm{CMCt})$ hydrogels were characterized by FTIR, SEM, DSC and swelling kinetics.
\end{abstract}

Keywords: Carboxymethyl chitosan (CMCt), Hydrogel, $\gamma$-ray radiation, Swelling, FTIR, SEM and DSC.

Hydrogels are three- dimensional structure of cross-linked polymer, which have affinity for water absorption ${ }^{(1)}$. The hydrogel matrix has been hold by chemical or physical cross-linking that involves hydrophilic groups of homopolymers or copolymers ${ }^{(2)}$. Hydrogels swell in water by retaining a significant fraction of water within the pores structure without dissolving ${ }^{(3)}$. Several applications for hydrogels have been developed in biomedical and industrial fields such as artificial implants, contact lenses, enzyme immobilization (4-6). Recent applications for hydrogels are interesting in drug delivery and agriculture in which water release from hydrogel is essential features ${ }^{(7-12)}$. Radiation crosslinking is considered as clean and effective method for hydrogel preparation. On comparison with conventional hydrogel preparation, cross-linking through irradiation process did not need initiators, or chemical cross-linking. Radiation methods are efficient and safe alternative for cross-linking without using toxic additives ${ }^{(13)}$. Lugao reviewed the application of radiation processing in preparing hydrogels ${ }^{(14)}$. It was shown that the radiation technique is a powerful tool for controlling the degree of cross-linking of the produced hydrogels. Hydrogels, biodegradable and biocompatible polymers, obtained by irradiation cross-linking have a variety of applications, in different fields, such as biomedical devices ${ }^{(15)}$ and control release of drug ${ }^{(16)}$.

\footnotetext{
*Corresponding author: abeermadel2003@yahoo.com
} 


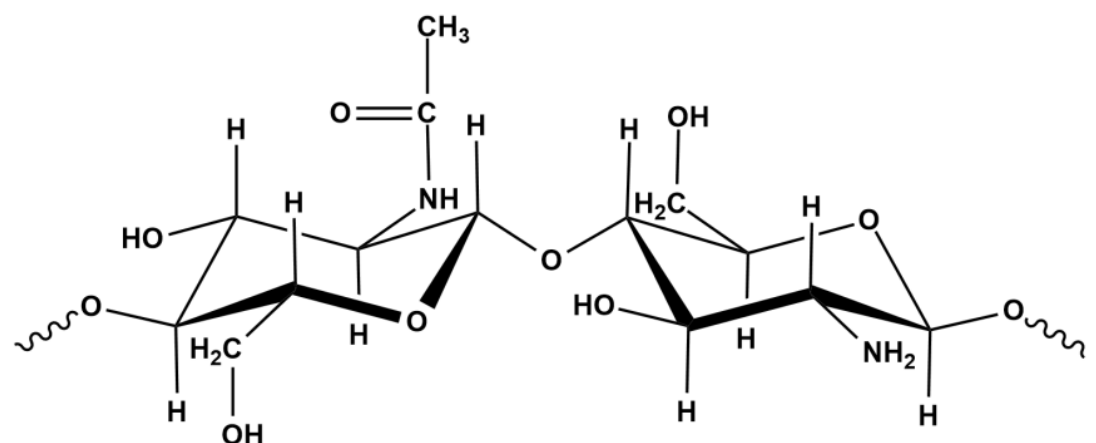

Scheme 1

Chitosan is a unique polysaccharide derived from deacetylation of chitin, structure of chitosan is shown in Scheme 1, the second most abundant natural polysaccharide ${ }^{(17)}$. Chitosan, as bio-based substrate has been used in wide varieties of applications in biomedical field ${ }^{(18,19)}$. The utilization of natural polymers has been preferred due to economic and sustainability point of view. Among the advantages of using natural polymer, chitosan is characterized by biocompatibility, biodegradability, and low toxicity ${ }^{(20,21)}$. The development of chitosan hydrogels has led to new drug delivery systems that release their payloads under varying environmental stimuli. Moreover, thermo-sensitive hydrogel variants have been developed to form a chitosan hydrogel in situ, precluding the need for surgical implantation ${ }^{(22)}$. Because of low solubility in water, chitosan-based hydrogels do not show high binding water capacities. Carboxymethylion of chitosan $(\mathrm{CMCt})$ can be performed by introducing $\mathrm{CH}_{2} \mathrm{COOH}$ onto active sites of chitosan moiety of $-\mathrm{OH}$ or/ and $-\mathrm{NH}_{2}$ groups. Therefore, CMCt can be used as a hydrophilic polymer with $\mathrm{pH}$ sensitive to prepare the $\mathrm{pH} /$ temperature-sensitive hydrogels with improved de-swelling rate $(23,24)$. CMCt are associated with environmental- friendly applications, due to its properties such as water solubility, biocompatibility, biodegradability, and antibacterial activity ${ }^{(25)}$.

The action of gamma irradiation on chitosan and CMCt has been manifested as remarkable degradation effect. High concentrated aqueous solutions have been required for preparing hydrogel based on chitosan and $\mathrm{CMCt}$ by utilization of gamma and electron beam irradiation ${ }^{(26)}$.

In the present work, CMCt was synthesized through carboxymethylation reaction for chitosan. Hydrogels have been prepared via cross-linking of carboxymethylated chitosan by using different doses of $\gamma$ - radiation for enhancing the water sorption capacity of this bio-polymer. The swelling behavior, FTIR, SEM and DSC of the prepared CMCt hydrogel have been investigated.

Egypt. J. Chem. 59, No.4 (2016) 
Materials

\section{Experimental}

Chitosan, commercial grade (Oxford Laboratory, India) with 90-95\% degree of deacetylation and MW 400,000 was used. Other chemicals used in the present work monochloroacetic acid, ethyl alcohol and sodium bicarbonate were of laboratory grade. All chemicals were used without further purification.

\section{Preparation of carboxymethyl chitosan (CMCt)}

$1 \mathrm{~g}$ of chitosan was swollen in $100 \mathrm{ml}$ water for a day, and then $0.5 \mathrm{~g}$ of $\mathrm{ClCH}_{2} \mathrm{COOH}$ was added, stirred until all the chitosan was highly swollen, then heated at $90^{\circ} \mathrm{C}$ for $3 \mathrm{hr}$ while keeping the $\mathrm{pH}$ at 8-8.5 by addition of $\mathrm{NaHCO}_{3}$ or $\mathrm{Na}_{2} \mathrm{CO}_{3}$, to give the product $\mathrm{CMCt}$. Then the reaction was stopped by cooling and water was discarded. Ethyl alcohol (80\%) was added and solid product was filtered and rinsed with 80-90\% ethyl alcohol to desalt and dewater, then it was air-dried at $25^{\circ} \mathrm{C}$.

\section{Sample preparation and $\gamma$-ray irradiation}

In a typical experiment for sample preparation, CMCt was mixed with deionized water to obtain homogenous paste. Due to the high solid content of CMCt, 25, 30, 35 and 40\%, the yielded paste was kneaded well with water by a glass bar. The prepared past samples were heat-sealed in a poly (vinylidene chloride) bag to prevent penetration of air to the sample during irradiation. After removal of air by a vacuum machine, the irradiation process was carried out using a Co-60 $\gamma$ cell at the National Center for Radiation Research and Technology, Cairo, Egypt with a dose rate $6.92 \mathrm{KG} / \mathrm{h}$. Irradiation was carried out under air atmosphere. The different past samples were exposed to different doses of $\gamma$ - irradiation $(10,20,25$ and $30 \mathrm{KG})$.

\section{Swelling behavior evaluation}

A dry weight of CMCt hydrogels sample $\left(\mathrm{W}_{\mathrm{o}}\right)$ was immersed in distilled water for different periods of time at room temperature until equilibrium. After the excessive surface water was removed with filter paper, the weight of swollen gel was determined $\left(\mathrm{W}_{\mathrm{s}}\right)$. The equilibrium degree of swelling was determined according to Eq. (1):

$$
\text { Degree of swelling } \%=\left[\mathrm{W}_{\mathrm{s}}-\mathrm{W}_{\mathrm{o}} / \mathrm{W}_{\mathrm{o}}\right] \mathrm{X} 100 \quad \text { Eq. (1) }
$$

\section{Determination of gel fraction for CMCt hydrogels}

The gel fraction of CMCt hydrogels was estimated by measuring its insoluble part after extraction. A dry weight of hydrogels $\left(\mathrm{W}_{\mathrm{o}}\right)$ was immersed in distilled water at $60^{\circ} \mathrm{C}$ for $24 \mathrm{hr}$ in order to remove the soluble part. The remaining gel was then dried at $25^{\circ} \mathrm{C}$ to a constant weight $\left(\mathrm{W}_{\mathrm{g}}\right)$. The gel fraction was calculated using Eq. (2):

$$
\text { Gel fraction } \%=\left[\mathrm{W}_{\mathrm{g}} / \mathrm{W}_{\mathrm{o}}\right] \mathrm{X} 100
$$


FTIR analysis

Chitosan, carboxymethyl chitosan and CMCt hydrogels, after removing sol part, were characterized of by FTIR. The spectra of the samples were taken in the solid state using potassium bromide pellets with a Fourier transform infrared spectroscope Jasco FT/IR, Nicolet, and Model 670.

Differential scanning calorimetry (DSC) analysis

DSC measurements were performed on SDT Q600/USA Differential Scanning Calorimeter.

Scanning electron microscopy (SEM)

The dried hydrogels were examined with JEOL JSM-5400 scanning electron microscopy (SEM). The surfaces of the polymers were sputter coated with gold for $3 \mathrm{~min}$.

The wet samples were fixed in $4 \%$ glutaraldehyde in $0.2 \mathrm{M}$ sodium cacodylate buffer ( $\mathrm{pH} 7.3$ ) for $4 \mathrm{hr}$, after two rinses in the same buffer for a period of $20 \mathrm{~min}$ followed by post fixation in osmium tetra-oxide $\mathrm{OsO}_{4}$ for $2 \mathrm{hr}$. Then the samples are washed three times for $30 \mathrm{~min}$ in the same buffer (sodium cacodylate buffer). The samples are then dehydrated in ascending grades of ethanol; from 10 to $100 \%, 10 \mathrm{~min}$ in each one except the finely one $100 \%$ for 30 minutes for three changes (each one for $10 \mathrm{~min}$ ).

\section{Results and Discussion}

Preparation and characterization of $C M C t$

When monochloroacetic acid $\left(\mathrm{ClCH}_{2} \mathrm{COOH}\right)$ is used to produce $\mathrm{CMCt}$, the carboxymethylation may occur on both $-\mathrm{NH}_{2}$ and $-\mathrm{OH}$ sites, where the produced $\mathrm{CMCt}$ are called $\mathrm{N}$-carboxymethyl and O-carboxymethyl chitosan, respectively as follows in Scheme ${ }^{(27)}$ :

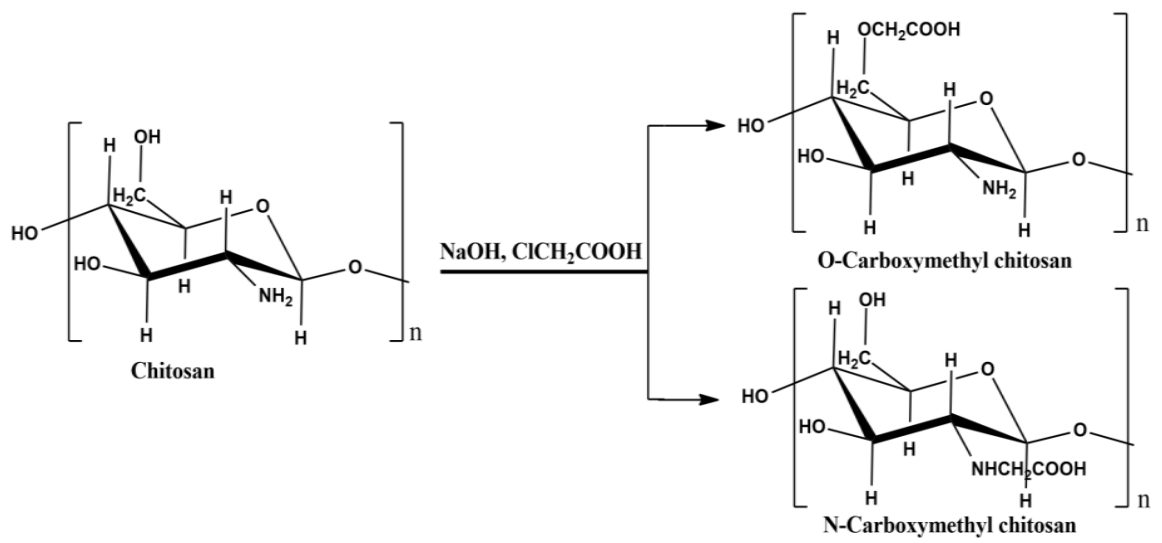

Scheme 2

Egypt. J. Chem. 59, No.4 (2016) 
It is therefore important to measure the proportion of these groups in the $\mathrm{CMCt}$ chains. For this purpose, FTIR was used for characterization of the $\mathrm{CMCt}$ (28). Figure 1 shows a comparison of the FTIR spectra for chitosan, CMCt and CMCt hydrogels, FTIR spectroscopy was employed to detect the structural changes between them. The FTIR of chitosan (curve a) showed three absorption peaks at 1153,1100 , and $895 \mathrm{~cm}^{-1}$ which were peaks attributed to the saccharide structure. The very strong broad absorption peak in range of 3425-2917 $\mathrm{cm}^{-1}$ should be assigned to the stretching vibration of $-\mathrm{OH}$, the extension vibration of the $-\mathrm{NH}$, and the hydrogen bonds of polysaccharide. There were two absorption peaks, one peak at $1598 \mathrm{~cm}^{-1}$ was due to the -NH bending (amide II) and a peak at $1650 \mathrm{~cm}^{-1}$ was due to the $\mathrm{C}=\mathrm{O}$ stretching (amide I), which illustrated that chitosan, had a high deacetylation degree. The FTIR spectrum of CMCt (curve b) showed, a strong absorption peak at $1412 \mathrm{~cm}^{-1}$ which could be assigned to the symmetrical stretching vibration of $\mathrm{COO}^{-}$group. The peak related to $\mathrm{COO}^{-}$group (around $1555 \mathrm{~cm}^{-1}$ ) is referred to asymmetrical stretching vibration overlapped with the deforming vibration of $\mathrm{NH}_{2}$ at $1641 \mathrm{~cm}^{-1}$ to obtain a very strong peak. On comparison with the peaks of chitosan, the bands at $1641 \mathrm{~cm}^{-1}$ and $1412 \mathrm{~cm}^{-1}$ corresponding to the carboxyl group (which overlaps with $\mathrm{N}-\mathrm{H}$ bend) and $\mathrm{CH}_{2} \mathrm{COOH}$ group, respectively are intense in spectrum indicating carboxymethylation on both the amino and hydroxyl groups of chitosan. The C$\mathrm{O}$ absorption peak became stronger and moved to $1021 \mathrm{~cm}^{-1(29)}$.

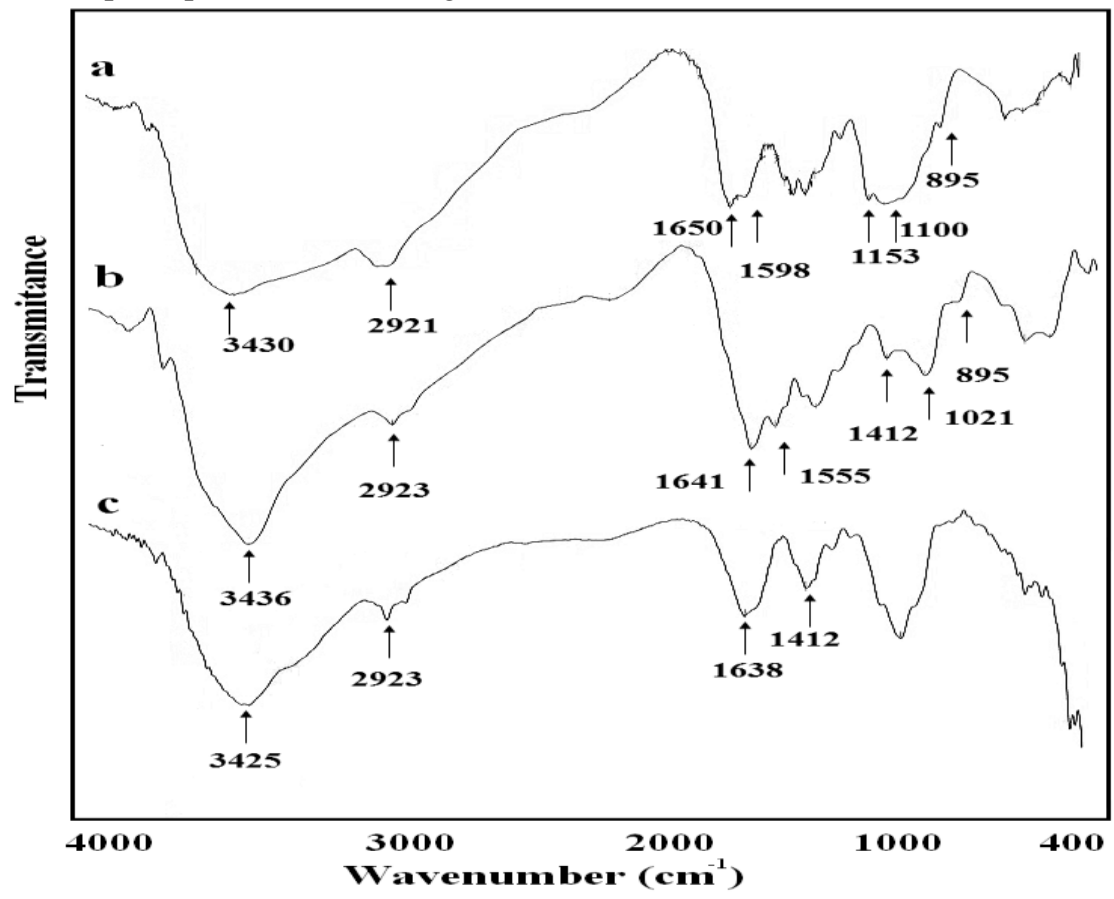

Fig. 1. FTIR spectroscopy for chitosan (a), CMCt (b) and $\gamma$-radiated CMCt $20 \mathrm{KG} \&$ $40 \%$ paste (c). 
Radiation-induced cross-linking for CMCt.

In aqueous solution, water absorbed most of irradiation energy. The crosslinking of $\mathrm{CMCt}$ was initiated by powerful oxidizing radicals, hydroxyl radicals $(\cdot \mathrm{OH})$ and hydrogen radicals $(\cdot \mathrm{H})$, which were formed by radiolysis of water as follows:

$$
\mathrm{H}_{2} \mathrm{O} \stackrel{\gamma \text {-ray }}{\longrightarrow} \mathrm{e}^{-}{ }_{\text {aq }}, \mathrm{OH}, \mathrm{H}, \mathrm{H}_{2} \mathrm{O}_{2}, \mathrm{H}_{2}, \mathrm{H}_{3} \mathrm{O}^{+}
$$

The incorporation of water into $\mathrm{CMCt}$ system is necessary for the crosslinking because the radiolysis of water generates active species to induce more $\mathrm{CMCt}$ macro-radicals by indirect effect. These active radicals react with $\mathrm{CMCt}$ and lead to the scission of main chain of CMCt. The induced oxidizing radicals attack the $\beta$ (1-4) glycosidic bonds of chitosan and reduce significantly its molecular weight consequently degradation of chitosan macromolecules is achieved $^{(30)}$.

The most probable reaction pathway of chain cleavage of CMCt is expected to follow the general procedure in Scheme 3. The main mechanism is $\mathrm{H}$ - removal stage, fragmentation and/or rearrangement of radicals at C (1), C (2), C (4), and $\mathrm{C}$ (5), which is similar to the degradation of chitosan. From Scheme 3, it also can be found that the degradation of CMCt induces the formation of carbonyl groups at the terminal chains and simultaneously, hydroxyl groups were formed at $\mathrm{C}$ (2) ${ }^{(31)}$. In our study, it was found that CMCt concentration of 30 to $40 \%$ resulted in the optimized CMCt hydrogels based on the swelling properties.
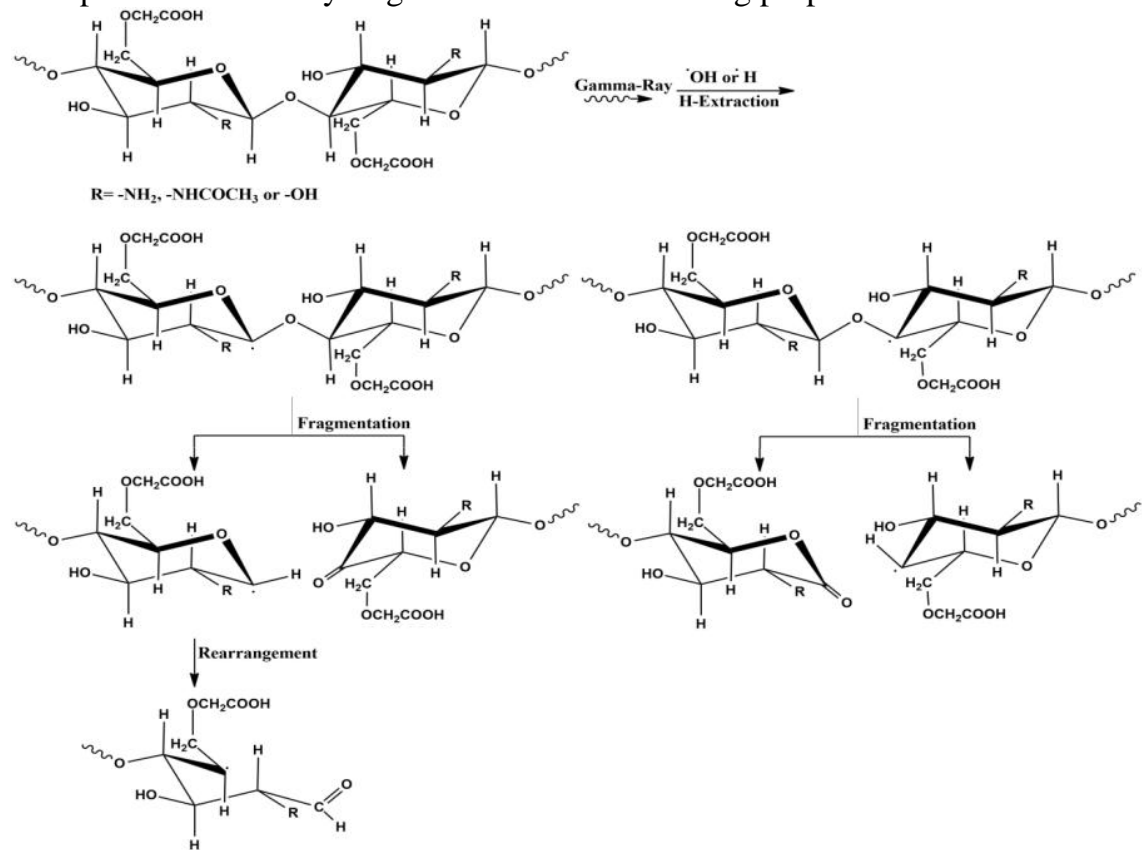

Scheme 3. The possible mechanism of main chain scission of CMCt during radiation.

Egypt. J. Chem. 59, No.4 (2016) 


\section{Gel fraction of CMCt hydrogels}

$\gamma$ - ray radiation-induced cross-linking of $\mathrm{CMCt}$ was observed at paste-like state with the concentration of $\mathrm{CMCt}$ from $25 \%$ to $40 \%$. The effect of $\mathrm{CMCt}$ concentration and the dose of $\gamma$ - ray radiation on gel fraction of $\mathrm{CMCt}$ hydrogels were shown in Fig. 2. Gel fraction of the obtained hydrogels increased from 45 to $58 \%$ as the paste concentration of CMCt increased from 25 to $35 \%$, respectively. As shown, when the concentration of CMCt increases from $35 \%$ to $40 \%$, low gel fraction was obtained at doses 20,25 and $30 \mathrm{KG}$ because $\mathrm{CMCt}$ and water could no longer form homogeneous mixture.

Figure 2 showed that the gel fraction increased with the increase of the dose from zero to $20 \mathrm{KG}$ after which the gel fraction results pass through maximum and then leveled off at high dose for each concentration of paste sample. This resulted in $\mathrm{CMCt}$ macro-radicals formation for cross-linking of $\mathrm{CMCt}$ at higher dose.

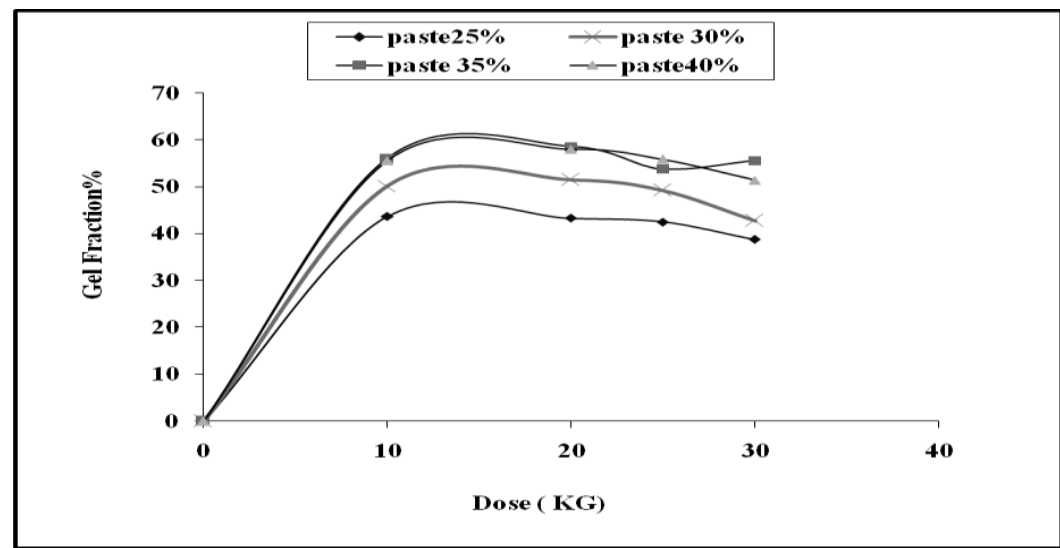

Fig. 2. The relation between gel fraction and dose (KG) for pastes $25,30,35$ and $40 \%$.

\section{Swelling behavior of CMCt hydrogels.}

The swelling property is very important for the applicability of the $\gamma$-ray irradiated CMCt hydrogels and the swelling ratio of hydrogels is affected by many factors such as the paste concentration, $\gamma$-ray irradiation dose, $\mathrm{pH}$, temperature and the time of swelling. Figure 3 gives the relation between the swelling ratio of the CMCt hydrogels of different pastes and $\gamma$-ray irradiation with different doses at neutral $\mathrm{pH}$ and for $12 \mathrm{hr}$. It can be seen that the swelling percentage increased with increasing dose in each concentrations, and the gel made from higher concentration aqueous solution (paste 30 and 40\%) shows higher swelling ability in water than that resulted from lower concentration solution. The swelling ability can be interpreted by increasing the cross-linking density of the obtained hydrogels from 30 to $40 \%$ aqueous solution. On the other hand the swelling percentages for all concentrations of $\mathrm{CMCt}$ hydrogels increased with increasing the dose of $\gamma$-ray irradiation to be maximum at $20 \mathrm{KG}$ dose after which decreasing of swelling percentages occurred by increasing the $\gamma$ ray irradiation dose from 20 to $30 \mathrm{KG}$. 


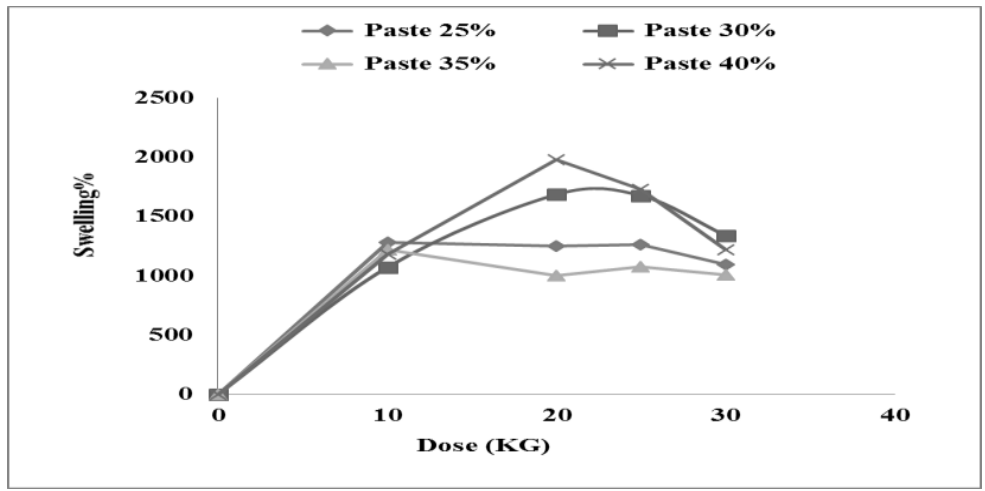

Fig. 3. Effect of gamma irradiation dose on the swelling \% of hydrogels.

Factors affecting the swelling behavior of CMCt hydrogels

$$
p H
$$

The effect of $\mathrm{pH}$ value on the swelling of CMCt hydrogel formed from 30 and $40 \%$ paste at irradiation dose $20 \mathrm{KG}$ and $12 \mathrm{hr}$ is shown in Fig. 4. As shown in the figure, the swelling features of $\mathrm{CMCt}$ hydrogels indicated $\mathrm{pH}$-sensitivity. The $\mathrm{CMCt}$ hydrogel swelled slightly in acidic medium ( $\mathrm{pH}$ less than 7), while remarkable increase in swelling percentage in alkali medium was obtained ( $\mathrm{pH}$ more than 8 ). The highest swelling ratio was obtained in the alkaline medium at $\mathrm{pH} 12$.

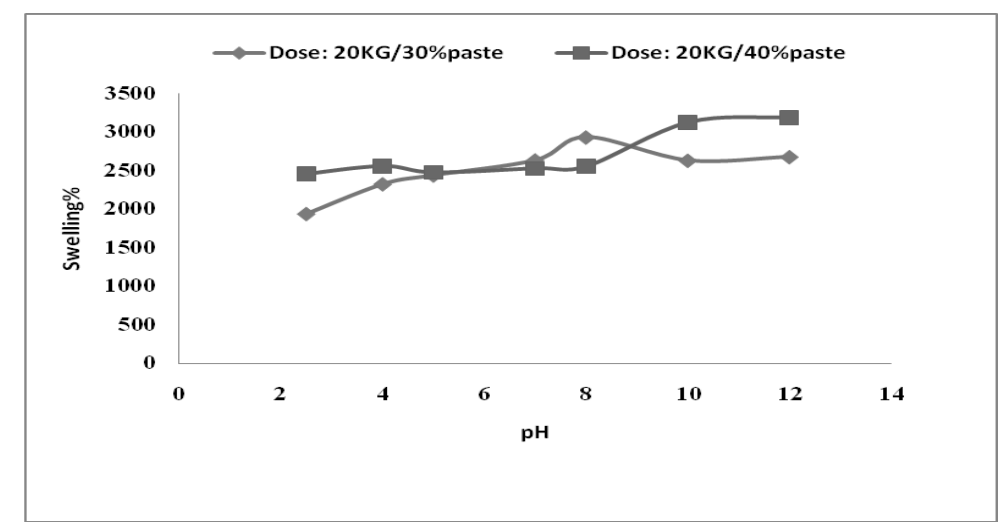

Fig. 4. Effect of $\mathrm{pH}$ on the swelling\% of hydrogels formed by gamma irradiation at a dose of $20 \mathrm{KG}$ for pastes 30 and $40 \%$.

Time

The effect of time on the swelling ratio of CMCt hydrogel (30\% and $40 \%$ conc., $20 \mathrm{KG}$ ) at neutral $\mathrm{pH}$ is shown in Fig. 5. It is obvious from the figure that the swelling percentage increased from 1530 to 2640 and from 1420 to 2420 for $\mathrm{CMCt}$ hydrogel formed from 30 and $40 \%$ paste at irradiation dose $20 \mathrm{KG}$, in the studied time range $0.5 \mathrm{~min}-24 \mathrm{hr}$. The swelling of CMCt hydrogel is characterized by high rate of water absorption at the initial $4 \mathrm{hr}$ and then slowed down gradually as shown in Fig. 5. The swelling is steady for long time of swelling (up to $12 \mathrm{hr}$ ).

Egypt. J. Chem. 59, No.4 (2016) 


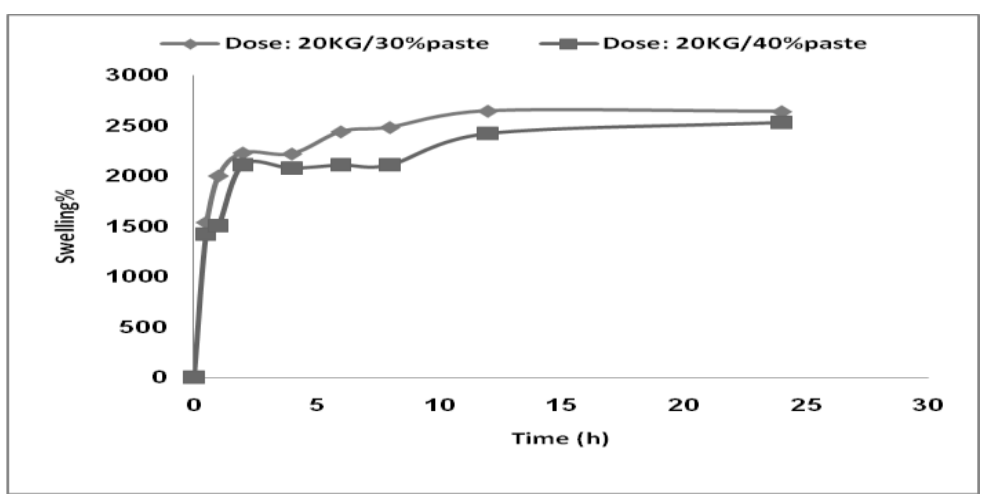

Fig. 5. Effect of time on the swelling\% of hydrogels formed by gamma irradiation at a dose of $20 \mathrm{KG}$ for pastes 30 and $40 \%$.

Characterization of CMCt hydrogel.

FTIR

Figure 1 shows FTIR spectra for $\gamma$ - radiated CMCt sample (20 KG \& 40\% paste). FTIR spectroscopy was employed to detect the structural changes between chitosan, $\mathrm{CMCt}$ and $\mathrm{CMCt}$ hydrogel. The FTIR spectra of $\gamma$-radiated CMCt hydrogel (curves c) are concerned. The broad band between 3420 and $3100 \mathrm{~cm}^{-1}$ due to the $-\mathrm{OH}$ stretching vibration is observed. This peak is referred to asymmetry stretching of alcoholic hydroxyl group bonded with water molecule in the hydrogel ${ }^{(32)}$. On the other hand, curve $\mathrm{c}$ shows a band at high wave number appeared at $1638 \mathrm{~cm}^{-1}$. Peaks at $1412 \mathrm{~cm}^{-1}$ were assigned to C-O stretch vibration of $-\mathrm{COOH}$. These changes in spectra revealed that although $\mathrm{CMCt}$ were cross-linked after irradiation, radiation degradation lead to formation of new carbonyl groups formed and some $-\mathrm{NH}_{2}$ were scissored out ${ }^{(32)}$.

Scanning electron microscopy observations

Microstructures of chitosan, CMCt and wet \& dry CMCt hydrogels surfaces were investigated by scanning electron microscopy as presented in Fig. 6 . The micrographs revealed that the surface structure of pure chitosan is nonporous, smooth and uneven and the texture is plain without pores (Fig. 6- a). The micrographs showed a drastic change after carboxymethylation as $\mathrm{CMCt}$ showed either a rough surface with a few undulations or a somewhat smooth surface with few wrinkles (Fig. 6- b). On the other hand, the micrographs of dry and wet $\mathrm{CMCt}$ hydrogels (Fig. 6- c, d respectively) are having entirely different morphology. It could be seen that the $\gamma$ - radiated CMCt hydrogels have a channel like surface with porous structure. The surface morphology of the pores of the hydrogels is different from that of CMCt. The distribution of porosity became uniform in case of wet CMCt hydrogel. SEM micrographs also revealed that the uniform porosity and channel like surface of wet CMCt hydrogels allows more water molecules to be absorbed. 

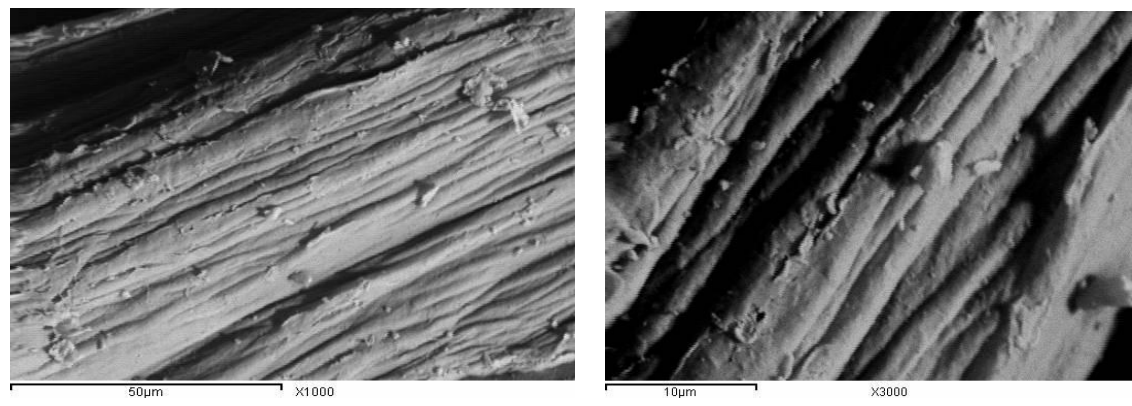

a- Chitosan
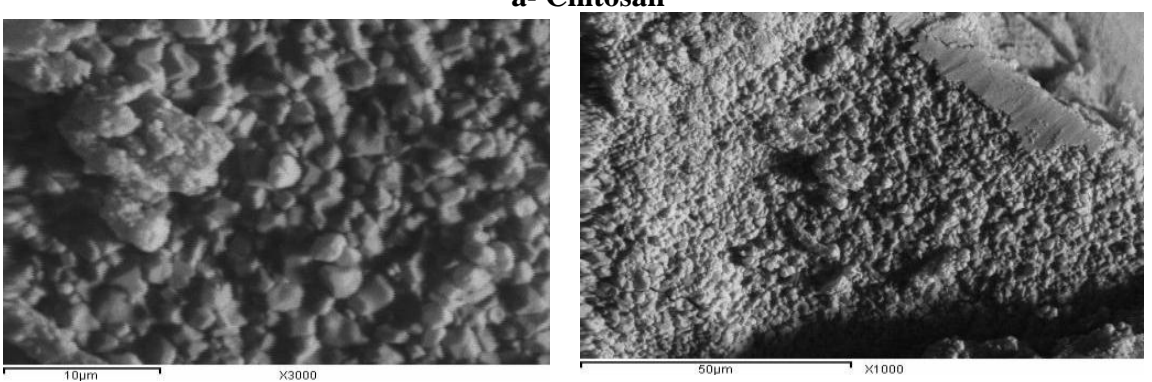

b- $\mathbf{C M C t}$
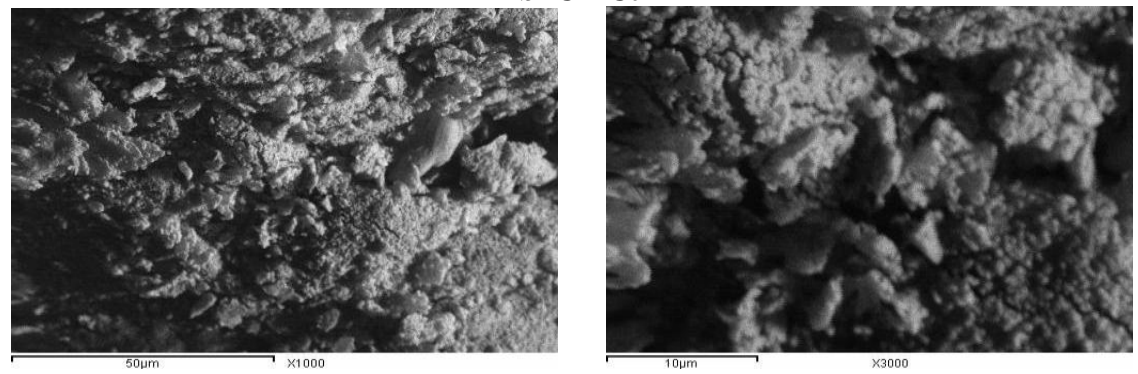

c- Dry CMCt hydrogel

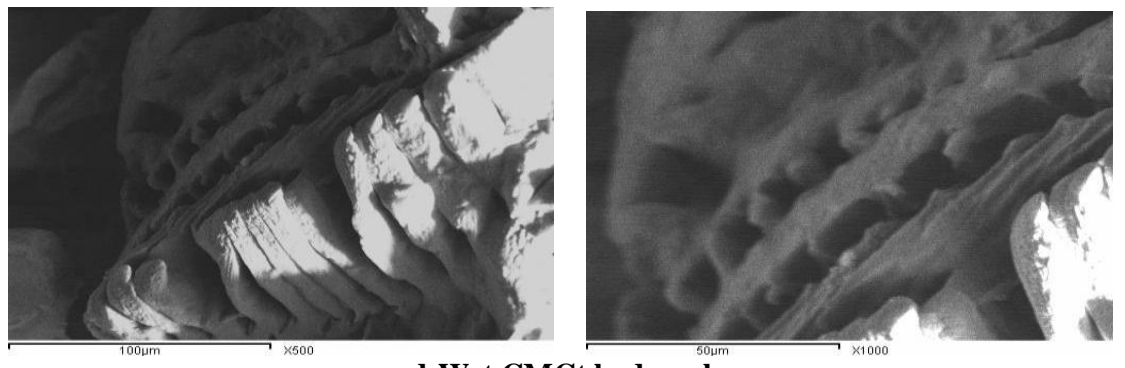

d-Wet CMCt hydrogel

Fig. 6. SEM micrographs of chitosan (a), CMCt (b), dry and wet CMCt hydrogels (c, d, respectively).

Egypt. J. Chem. 59, No.4 (2016) 


\section{Differential scanning calorimetry (DSC)}

DSC was demonstrated as an effective technique to detect the thermal transition for $\mathrm{CMCt}$ and $\gamma$ - radiated CMCt hydrogel. In the present study, the DSC were carried out for chitosan, CMCt and CMCt (20 KG\& 40\% paste) in the range of -50 to $200^{\circ} \mathrm{C}$ with $5 \mathrm{mg}$ of sample with a heating rate of $10^{\circ} \mathrm{C} / \mathrm{min}$ under $\mathrm{N}_{2}$. DSC spectra of chitosan (a), CMCt (b) and $\gamma$ - radiated CMCt $20 \mathrm{KG} \& 40 \%$ paste (c) are shown in Fig. 7. It is obvious from the figure that, besides the peaks indicating melting of water at about $5^{\circ} \mathrm{C}$, there were endothermic peaks at about $63.45,117.29$ and $151.33^{\circ} \mathrm{C}$ in the spectra of chitosan, $\mathrm{CMCt}$ and $\mathrm{CMCt}$ hydrogels, respectively. The temperatures ranged between $117-150^{\circ} \mathrm{C}$ in the spectrum of the $\mathrm{CMCt}$ and $\mathrm{CMCt}$ hydrogel reflect the changes in chemical and physical features for CMCt and $\gamma$ - radiated CMCt. This demonstrated that the obtained hydrogels have superior thermal stability than that for both chitosan and $\mathrm{CMCt}^{(33)}$.

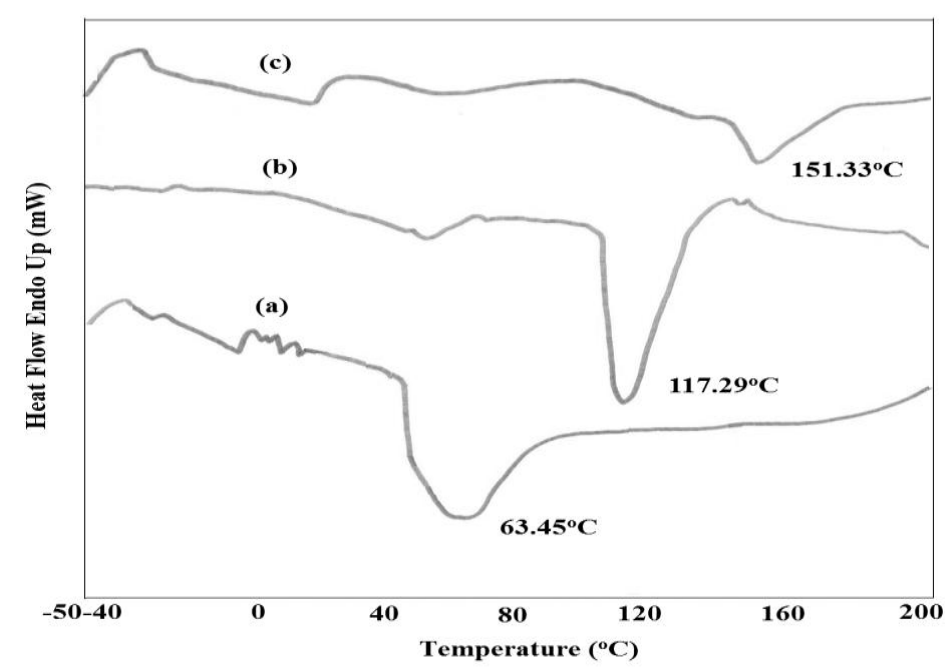

Fig. 7. DSC of chitosan (a), CMCt (b) and $\gamma$-radiated CMCt (c).

\section{Swelling kinetics}

The absorption of water molecules through the hydrogel network is dependent on the mode of diffusion. The swelling may be diffusion-controlled process in which the rate of diffusion is less than the rate of relaxation of hydrogel network matrix. This type of diffusion obeys Fickian law. On the other hand, when the relaxation rate exceeds the diffusion rate the diffusion mode is non-Fickian diffusion as shown in Fig. 8.

The swelling kinetics have been studied for swelling of two hydrogel samples, $\gamma$ - radiated CMCt hydrogels formed by gamma irradiation at a dose of $20 \mathrm{KG}$ $30 \%$ paste and $40 \%$ paste. Fick's law is applied according to the following equation ${ }^{(34)}$ : 


$$
\begin{gathered}
\mathrm{F}=\mathrm{W}_{\mathrm{t}} / \mathrm{W}_{\mathrm{e}}=\mathrm{Kt}^{\mathrm{n}} \\
\text { or } \ln \mathrm{F}=\ln \mathrm{K}+\mathrm{n} \ln \mathrm{t}
\end{gathered}
$$

where $\mathrm{W}_{\mathrm{t}}$ and $\mathrm{W}_{\mathrm{e}}$ are the amount of water uptake by the hydrogel at time $\mathrm{t}$ (seconds) and at equilibrium, $\mathrm{K}$ is a constant characteristic of the structure of the networks of hydrogel and $\mathrm{n}$ determines the mode of water diffusion.

The water diffusion nature into CMCt hydrogels was determined by applying Fick's law. As shown in Fig. 9, plotting ln F vs. ln t gives a straight line from which the intercept is equivalent to the constant $\mathrm{K}$ and the slope gives the number n. According to the Fick's law, a value of $n \leq 0.5$ indicates a Fickian diffusion mechanism in which the sorption is diffusion controlled, whereas a value of $0.5<$ $\mathrm{n}<1$ indicates an anomalous non-Fickian type diffusion and contributes to the water-sorption process. Figure 9 illustrates the application of the above equation to the CMCt hydrogels and the calculated values for $\mathrm{n}$ were 0.123 and 0.139 for $\gamma$ - irradiated CMCt hydrogels formed by gamma irradiation at a dose of $20 \mathrm{KG}$ for $30 \%$ paste and $40 \%$ paste, respectively. Therefore, it can be concluded that the diffusion of water into the prepared hydrogel is undergoing to Fickian diffusion and it depends on the pathways and the structures of pores formed in hydrogel networks. This behavior agreed with the morphological structure of the hydrogel surface presented in Fig. 6 d.

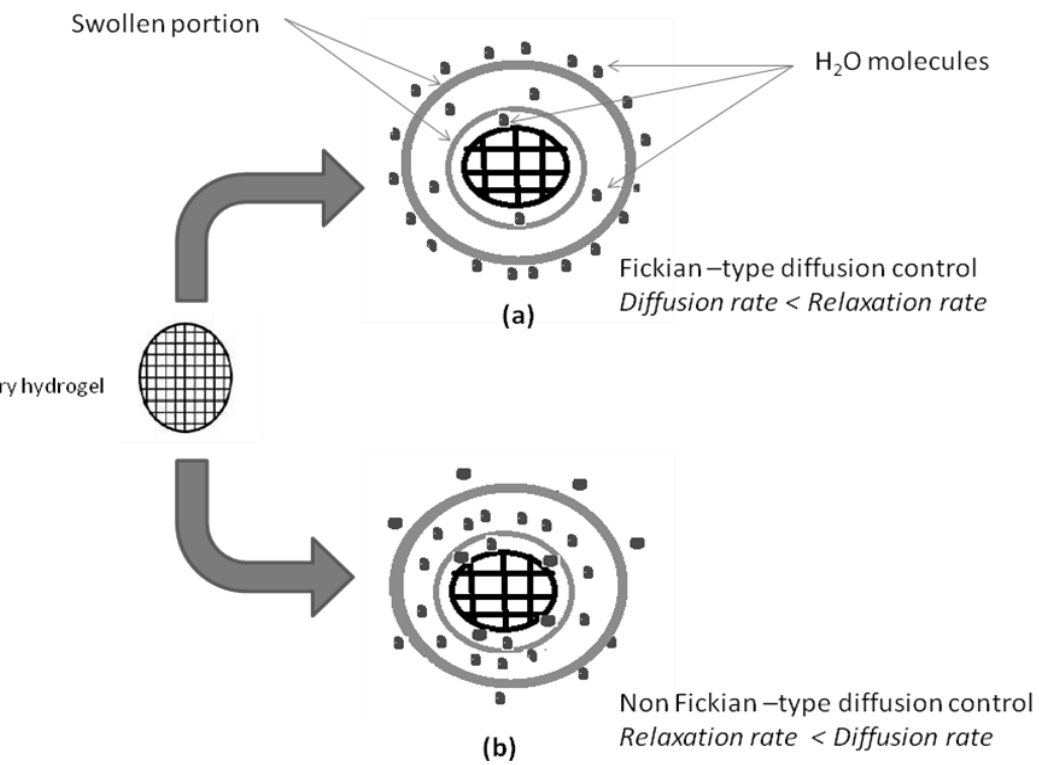

Fig. 8. Fickian (a) and non-Fickian (b) diffusion for hydrogel swelling. 


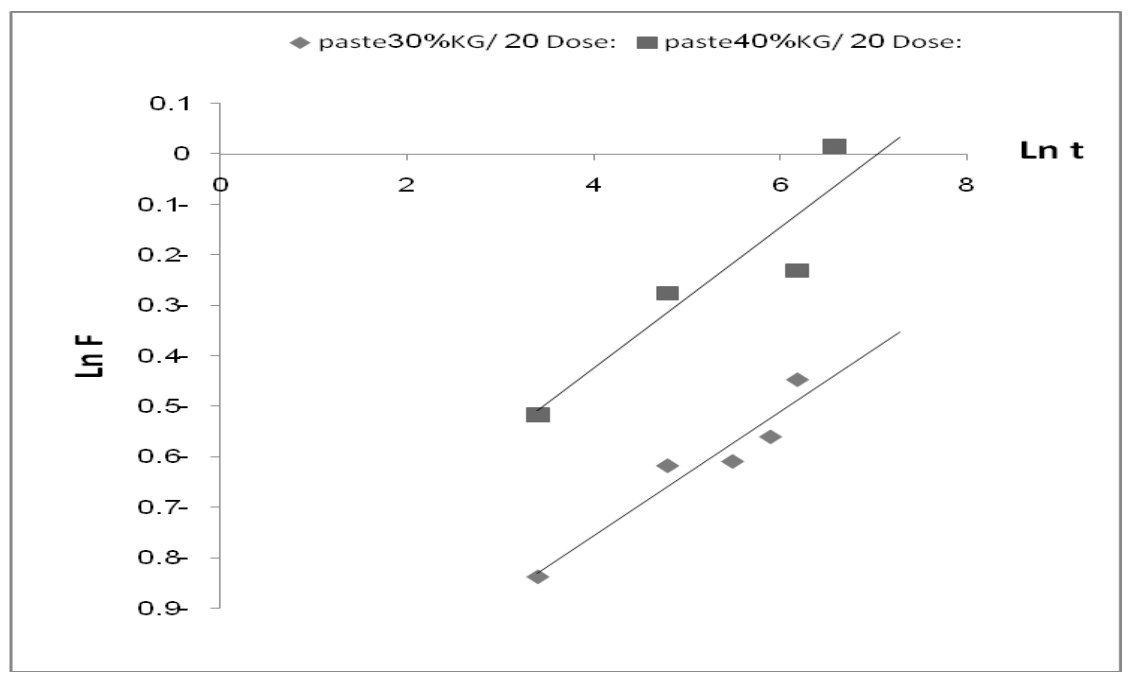

Fig. 9. Plot of $\mathrm{Ln} F$ versus $\mathrm{Ln} \mathrm{t}$ for CMCt hydrogels formed by gamma irradiation at a dose of $20 \mathrm{KG}$ for $30 \& 40 \%$ paste.

\section{Conclusion}

Chitosan was functionalized via carboxymethylation to improve the hydrophilicity that serves the aim of preparing of hydrogel. The substitution can occur at $\mathrm{N}$ or $\mathrm{O}$ positions, where the presence of carboxyl group enhanced the swelling properties of the prepared hydrogel. Efficient crosslinking of CMCt was achieved by different doses of $\gamma$ - radiation. The maximum increase in swelling percentage was obtained at $20 \mathrm{KG} \gamma$ - ray irradiation dose. SEM shows difference in microstructures for chitosan, $\mathrm{CMCt}$ and crosslinked $\mathrm{CMCt}$, wet and dry, surfaces. The swelling of hydrogel samples is Fickian type diffusion and it depends on the pathways and structures of pores formed in hydrogel networks.

\section{References}

1. Abd El-Mohdy, H.L., Water sorption behavior of CMC/PAM hydrogels prepared by $\gamma$ irradiation and release of potassium nitrate as agrochemical. React. Funct. Polym. 67, 1094-1102 (2007).

2. Langer, R. and Peppas, N.A., Advances in biomaterials, drug delivery, and bionanotechnology. AIChE J. 49, 2990-3006 (2003).

3. Farag, R.K. and Mohamed, R.R., Nanogels for swelling studies and antimicrobial activity. Molecules. 18, 190-20 (2013).

4. Salama, A., Shukry, N. and El-Sakhawy, M., Carboxymethyl cellulose-g- poly (2(dimethylamino) ethyl methacrylate) hydrogel as bioadsorbent for dye removal. Int. J. Biol. Macromol. 73, 72-75 (2015). 
5. Adel, A.M., Abou-Youssef, H., El-Gendy, A.A. and Nada, A.M., Carboxymethylated cellulose hydrogel; sorption behavior and characterization. Nat. Sci. 8, 245-256 (2010).

6. Moustafa, A.B., Kahil, T. and Faizalla, A., Preparation of porous polymeric structures for enzyme immobilization. J. Appl. Polym. Sci. 76, 594-601 (2000).

7. Montesano, F.F., Parente, A., Santamaria, P., Sannino, A. and Serio, F., Biodegradable superabsorbent hydrogel increases water retention properties of growing media and plant growth. Agric. Agric. Sci. Procedia. 4, 451-458 (2015).

8. Salama, A. and El-Sakhawy, M., Preparation of polyelectrolyte/calcium phosphate hybrids for drug delivery application. Carbohyd. Polym. 113, 500-506 (2014).

9. Raafat, A.I., Eid, M. and El-Arnaouty, M.B., Radiation synthesis of superabsorbent CMC based hydrogels for agriculture applications. Nucl. Instrum. Methods B. 283, 7176 (2012).

10. Saraydin, D., Karadağ, E. and Güven, O., The releases of agrochemicals from radiation induced acrylamide crotonic acid hydrogels. Polym. Bull. 41, 577-584 (1998).

11. Ahmed, E.M., Hydrogel: preparation, characterization, and applications: A review. $J$. Adv. Res. 6, 105-121 (2015).

12. Jagur-Grodzinski, J., Polymeric gels and hydrogels for biomedical and pharmaceutical applications. Polym. Adv. Technol. 21,_27-47 (2010).

13. Wang, M., Xu, L. Zhai, M., Peng, J. Li and Wei, J.G., $\gamma$-ray radiation-induced synthesis and $\mathrm{Fe}$ (III) ion adsorption of carboxymethylated chitosan hydrogels. Carbohyd. Polym.. 74, 498-503 (2008).

14. Lugao, A.B. and Malmonge, S.M., Use of radiation in the production of hydrogels. Nucl. Instrum. Methods B. 185, 37-42 (2001).

15. Liu P., Peng J., Li J. and Wu J., Radiation cross-linking of CMC-Na at low dose and its application as substitute for hydrogel. Radiat. Phys. Chem. 72, 635-638 (2005).

16. Savas, H. and Guven, O., Investigation of active substance release from poly (ethylene oxide) hydrogels. Int. J. Pharm. 224, 151-158 (2001).

17. Adel, A.M., Dupont, A.L., Abou-Yousef, H., El-Gendy, A., Paris, S. and ElShinnawy, N., A study of wet and dry strength properties of unaged and hygrothermally aged paper sheets reinforced with biopolymer composites. J. Appl. Polym. Sci. 131, 9212-9224 (2014).

18. Mi, F.L., Shyu, S.S., Wu, Y.B., Lee, S.T., Shyong, J.Y. and Huang, R.N., Fabrication and characterization of sponge- like asymmetric chitosan membrane as a wound dressing. Biomaterials. 22, 165-173 (2001).

19. Muzzarelli, R.A.A., Biochemical significance of exogenous chitin in animals and patients. Carbohyd. Polym. 20, 7-16 (1993).

Egypt. J. Chem. 59, No.4 (2016) 
20. Kim, S.J., Shin, S.R., Lee, Y.M. and Kim, S.I., Swelling characterizations of chitosan and polyacrylonitrile semi-interpenetrating polymer network hydrogels. $J$. Appl. Polym. Sci. 87, 2011-2015 (2003).

21. Nada, A. M. A., El-Sakhawy, M., Kamel, S., Eid, M. A. M. and Adel A. M. Mechanical and electrical properties of paper sheets treated with chitosan and its derivatives, Carbohyd. Polym. 63, 113-121 (2006).

22. Bhattarai, N., Gunn, J. and Zhang, M., Chitosan-based hydrogels for controlled, localized drug delivery. Adv. Drug Deliv. Rev. 62, 83-99 (2010).

23. Lee, W.F. and Chiang, W.H., Swelling and drug-release behavior of the poly (AAco-N-vinyl pyrrolidone)/chitosan interpenetrating polymer network hydrogels. J. Appl. Polym. Sci. 91, 2135-2142 (2004).

24. Chen, L.Y., Du, Y.M., Wu, H.Q. and Xiao, L., Relationship between molecular structure and moisture retention ability of carboxymethyl chitin and chitosan. J. Appl. Polym. Sci. 83, 1233-1241 (2002).

25. Riccardo, A.A.M., Chitins and Chitosans as Immunoadjuvants and Non-Allergenic Drug Carriers. Mar. Drugs. 8, 292-312 (2010).

26. Hiroki, A., Tran, H.T., Nagasawa, N., Yagi, T. and Tamad, M., Meta adsorption of carboxymethyl cellulose/carboxymethyl chitosan hydrogels prepared by Gamma irradiation. Radiat. Phys. Chem. 78, 1076-1080 (2009).

27. Upadhyaya, L., Singh, J., Agarwal, V. and Tewari, R.P., Biomedical applications of carboxymethyl chitosans. Carbohyd. Polym. 91, 452-466 (2013).

28. Zamani, A., Henriksson, D. and Taherzadeh, M.J., A new foaming technique for production of superabsorbents from carboxymethyl chitosan. Carbohyd. Polym. 80, 1091-1101 (2010).

29. Mourya, V.K., Inamdar, N.N. and Tiwarih, A., Carboxymethyl chitosan and its applications. Adv. Mater. Lett. 1, 11-33 (2010).

30. Huang, L., Peng, J., Zhai, M., Li, J. and Wei, G., Radiation-induced changes in carboxymethylated chitosan. Radiat. Phys. Chem. 76, 1679-1683 (2007).

31. Tahtat, D., Mahlous, M., Benamer, S., Khodja, A.N. and Youcef, S.L., Effect of molecular weight on radiation chemical degradation yield of chain scission of $\gamma$ irradiated chitosan in solid state and in aqueous solution. Radiat. Phys. Chem. 81, 659665 (2012).

32. Huang, L., Zhai, M., Peng, J., Li, J. and Wei, G., Radiation-induced degradation of carboxymethylated chitosan in aqueous solution. Carbohydr. Polym. 67, 305-312 (2007).

33. Wang, M., Xu, L., Ju, X., Peng, J., Zhaia, M., Li, J. and Wei, G., Enhanced radiation crosslinking of carboxymethylated chitosan in the presence of acids or polyfunctional monomers. Polym. Degrad. Stabil. 93, 1807-1813 (2008). 
34. El-Din, H.M.N., Abd Alla, S.G. and El-Naggar, A.W.M., Swelling and drug release properties of acrylamide/carboxymethyl cellulose networks formed by gamma irradiation. Radiat. Phys. Chem. 79, 725-730 (2010).

\section{الهيدروجل المحضر على اساس كتلة حيوية باستخدام شعاع الجاما

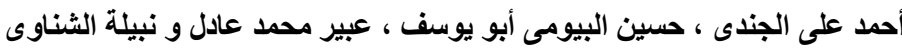 قسم السليلوز و الورق ـ المركز القومى للبحوث -33 شارع البحوث ـ الدقى ـ الجيزة.}

لقد تم تحضير الكربوكسى ميثيل كينوزان من خلال تفاعل الكربوكسى ميثيلان

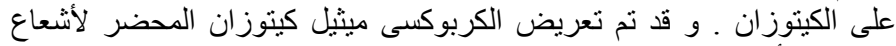

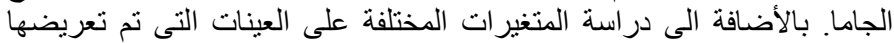

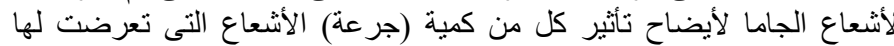

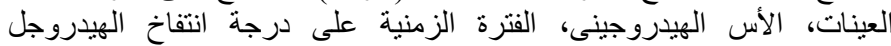

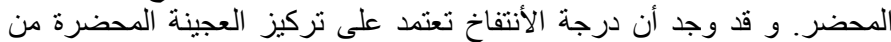

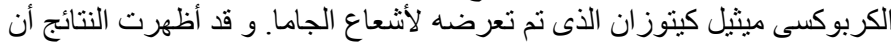

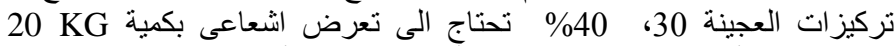

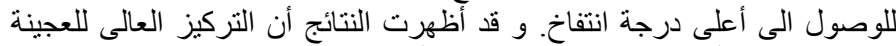

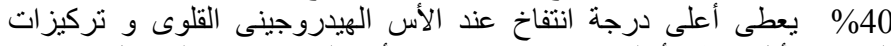

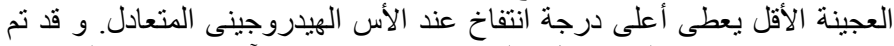

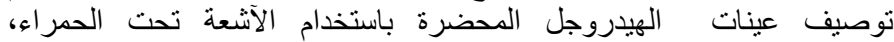

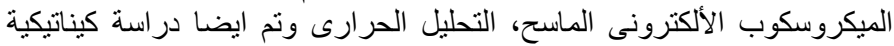
عينات الهيدروجل المحضرة من الكربوكسى ميثيل كيتوز ان. 